\title{
Land-Use Type Drives Soil Population Structures of the Entomopathogenic Fungal Genus Metarhizium
}

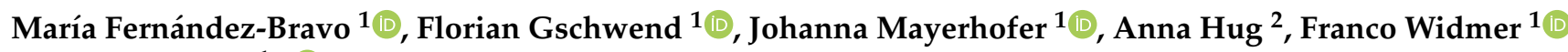 \\ and Jürg Enkerli 1,*(D) \\ 1 Molecular Ecology, Agroscope, CH-8046 Zürich, Switzerland; \\ mariadelcarmen.fernandezbravo@agroscope.admin.ch (M.F.-B.); \\ florian.gschwend@agroscope.admin.ch (F.G.); johanna.mayerhofer@agroscope.admin.ch (J.M.); \\ franco.widmer@agroscope.admin.ch (F.W.) \\ 2 Swiss Soil Monitoring Network (NABO), Agroscope, CH-8046 Zürich, Switzerland; \\ anna.hug@agroscope.admin.ch \\ * Correspondence: juerg.enkerli@agroscope.admin.ch
}

Citation: Fernández-Bravo, M.; Gschwend, F.; Mayerhofer, J.; Hug, A.; Widmer, F.; Enkerli, J. Land-Use Type Drives Soil Population Structures of the Entomopathogenic Fungal Genus Metarhizium. Microorganisms 2021, 9, 1380. https://doi.org/10.3390/ microorganisms 9071380

Academic Editor: Victor Glupov

Received: 28 May 2021

Accepted: 22 June 2021

Published: 25 June 2021

Publisher's Note: MDPI stays neutral with regard to jurisdictional claims in published maps and institutional affiliations.

Copyright: (c) 2021 by the authors. Licensee MDPI, Basel, Switzerland. This article is an open access article distributed under the terms and conditions of the Creative Commons Attribution (CC BY) license (https:// creativecommons.org/licenses/by/ $4.0 /)$.

\begin{abstract}
Species of the fungal genus Metarhizium are globally distributed pathogens of arthropods, and a number of biological control products based on these fungi have been commercialized to control a variety of pest arthropods. In this study, we investigate the abundance and population structure of Metarhizium spp. in three land-use types—arable land, grassland, and forest-to provide detailed information on habitat selection and the factors that drive the occurrence and abundance of Metarhizium spp. in soil. At 10 sites of each land-use type, which are all part of the Swiss national soil-monitoring network (NABO), Metarhizium spp. were present at 8, 10, and 4 sites, respectively. On average, Metarhizium spp. were most abundant in grassland, followed by forest and then arable land; 349 Metarhizium isolates were collected from the 30 sites, and sequence analyses of the nuclear translation elongation factor $1 \alpha$ gene, as well as microsatellite-based genotyping, revealed the presence of 13 Metarhizium brunneum, 6 Metarhizium robertsii, and 3 Metarhizium guizhouense multilocus genotypes (MLGs). With 259 isolates, M. brunneum was the most abundant species, and significant differences were detected in population structures between forested and unforested sites. Among 15 environmental factors assessed, C:N ratio, basal respiration, total carbon, organic carbon, and bulk density significantly explained the variation among the M. brunneum populations. The information gained in this study will support the selection of best-adapted isolates as biological control agents and will provide additional criteria for the adaptation or development of new pest control strategies.
\end{abstract}

Keywords: M. brunneum; M. robertsii; M. guizhouense; microsatellite; SSR; EF-1alpha; abiotic factors; arable land; grassland; forest; biological control

\section{Introduction}

The genus Metarhizium Sorokīn (Hypocreales: Clavicipitaceae) includes more than 30 described species (including both asexual and sexual states) that are pathogenic to arthropods, particularly insects and some arachnids [1,2]. The wide host spectrum of Metarhizium spp. includes many important crop pests such as Helicoverpa armigera (Hübner, 1805), Diabrotica virgifera virgifera (LeConte, 1868), Agriotes spp. (Eschscholtz, 1829), and also termites, cockroaches, and even disease-transmitting insects such as tse-tse flies [2-7]. Based on the pathogenicity of this fungus, a number of biological control agents have been developed as commercial mycoinsecticides and mycoacaricides to control pest arthropods worldwide (see [8] and https:/ / www.eppo.int; https:/ / www.epa.gov).

Soil is considered the main habitat and reservoir of Metarhizium spp., and they have been isolated from very different ecosystems, from tropical to temperate, semiarid, and artic areas [5,9]. Besides being entomopathogenic, Metarhizium spp. exhibit a pronounced 
saprophytic lifestyle, and, for some isolates and/or species, symbiotic interactions with plants as rhizosphere colonizers and/or endophytes have been reported [9,10]. Studies have demonstrated, for instance, that isolates of $M$. robertsii J.F. Bisch., S.A. Rehner \& Humber, M. brunneum Petch, and M. guizhouense Q.T. Chen \& H.L. Guo can provide insectderived nitrogen to plants [11,12], increase plant growth and productivity $[13,14]$, as well as protect plants from environmental stresses, for example, in saline environments $[15,16]$. The versatile roles Metarhizium spp. may have emphasize the beneficial potential and value of its presence, particularly in agricultural habitats [17].

Arable land, grassland, and forests represent major anthropogenic land-use types (LUTs) and cover about $40 \%$ of the global land area [18]. A number of studies have reported possible effects of LUTs on the presence and abundance of Metarhizium spp. Factores responsible includ crop types, farming practices management intensity, tillage, and the application of pesticides or fertilizers [19-22]. For instance, it has been consistently reported that Metarhizium spp. occur at higher abundances in unforested, sun-exposed LUTs or open land areas such as arable- and grasslands compared to forests, where their abundances are lower or sometimes not even detected [17,19,23-26]. The abundance of Metarhizium spp. has been more prominent in unforested semi-natural habitats such as permanent grassland and field margins compared to arable land in Switzerland [27,28]. Furthermore, there is evidence from field studies in Norway indicating a higher abundance of entomopathogenic fungi such as M. anisopliae, Beauveria bassiana (Bals.-Criv.) Vuill., or Tolypocladium cylindrosporum W. Gams in soils of organically managed fields compared to conventionally managed fields [29]. Several studies have suggested that the application of organic fertilizers may be the main driving factor for the increased abundance of Metarhizium spp. [22,30].

While the overall abundance of Metarhizium spp. in different LUTs has been explored in various studies, information on the species composition of Metarhizium communities and within-species diversity in different LUTs is limited. In addition, many of these studies have been performed prior to the establishment of the current Metarhizium species concept, which has precluded a comparison of data from these different periods. Nevertheless, the results reported by Cabrera-Mora et al. [31] have indicated that cropping systems can affect species abundances, as M. brunneum was isolated predominantly from soil where beans were grown and $M$. robertsii from soils where maize was grown. Similarly, Wyrebek et al. [32] reported that M. robertsii, M. brunneum, and M. guizhouense were closely associated with soils from grassland, shrubs, or trees, respectively. In a study performed in Ontario, Canada, two genetically distinct groups were found to be associated with agricultural unforested field habitats and forested soils, respectively [23,33,34]. Isolates of the two genetic groups were subsequently described as M. brunneum and M. robertsii [35]. Studies assessing within-species diversity have mostly focused on individual fields or agricultural systems only, e.g., an agricultural field in Denmark [36] and a strawberry field in Brazil [37]. A comparison of the within-species diversity of M. brunneum and M. robertii between agricultural and adjacent natural habitats has been performed in different ecological regions in northwestern North America [38]. While considerable genotype diversity has been reported for both species in both habitats, no significant differences have been detected between them. Information on the number of species, their population structures, and distributions in different LUTs remains limited. This information, however, is important to understand the interaction of ecological conditions and Metarhizium population structures. In turn, it may allow the improvement of existing habitats or the development of new habitats and/or LUT-adapted biological control approaches, including conservation biological control [17].

Conditions in a particular soil or at a particular site are affected, on the one hand, by anthropogenic activities and, on the other hand, by different environmental factors, i.e., abiotic (physical and chemical), biotic (derived from organisms), as well as climatic (humidity, temperature, and solar radiation) factors. All these factors may have direct effects on the occurrence, abundance, propagation, persistence, and even virulence of Metarhizium populations [24,39-42]. Soil physical, chemical, and biological factors, such 
as soil texture, $\mathrm{pH}$, and organic matter content, belong to the most intensively studied factors in this context. However, various reports have not been able to provide consistent information, and, in many cases, they have been contradictory. For example, organic matter, which represents an important source of organic carbon in soil, has been reported to negatively correlate with the abundance of Metarhizium in agricultural land in Pennsylvania, USA [20], whereas other studies have reported positive correlations to agricultural land, grassland, and forests in Spain [24]. Similarly, the C:N ratio, a soil factor directly related to the quality of organic matter, has been reported to positively correlate with the abundance of entomopathogenic fungi in soil [43]. In that study, the C:N ratio was proposed as a predictor of Metarhizium spp. abundance in vineyard soils; however, whether this concept may generally be applicable to vineyards or even other habitats or LUTs such as grassland and arable land or even forests is currently not clear. The effect of soil pH on microbial populations is well documented; however, data on the specific effects of $\mathrm{pH}$ on Metarhizium abundance are currently not conclusive. While some studies suggest that Metarhizium prefer more alkaline environments, others have reported that Metarhizium are more adapted to acidic conditions or are not even responsive to $\mathrm{pH}[24,44]$.

In the present study, we determine Metarhizium spp. abundance and population structure at 30 different monitoring sites of the Swiss soil-monitoring network (NABO) that equally represent arable land, grassland, and forest. The overall goal was to obtain profound information on habitat selectivity and the factors that may drive population structures and the abundance of this important entomopathogenic fungal genus. Our specific goals were to: (1) determine Metarhizium spp. abundance as well as species diversity and population structures at the 30 sites across Switzerland, (2) investigate the differences among and within LUTs in detected Metarhizium populations, and (3) assess the extent to which soil physical, chemical, and biological factors may explain the differences observed.

\section{Materials and Methods}

\subsection{Sampling Sites, Sampling Procedure}

The Swiss soil-monitoring network (NABO, www.nabo.ch), established in 1984, monitors 103 sites for physical, chemical, and biological parameters (biomass, soil respiration) [45]. The sites represent three different LUTs, i.e., arable land, permanent grassland, and forest, which dominate and characterize the landscape in the midlands and pre-alpine areas in Switzerland. In 2012, the NABO was complemented with the NABObio initiative to monitor soil microbial biodiversity at $30 \mathrm{NABO}$ sites (10 sites of each of the three LUTs) (Figure S1) [46].

Sampling was carried out in spring after snowmelt and before the first fertilization, starting in Ticino (south of Switzerland) at the beginning of February 2016 and finishing in Grindelwald (alpine area) at the end of June 2016. This sampling scheme was implemented to harmonize time points in relation to the vegetation status of individual sites, i.e., the beginning of vegetation growth. Three composite samples were collected at each of the 30 sites. Composite samples consisted of 25 bulked soil cores $(2.5 \mathrm{~cm}$ diameter $\times 20 \mathrm{~cm}$ depth) that were taken evenly distributed in a georeferenced $10 \times 10 \mathrm{~m}$ plot, according to the standardized sampling protocol of NABO sampling [47]. In total, 90 composite samples were collected (Table S1) and transported to the laboratory immediately after sampling and kept at $4{ }^{\circ} \mathrm{C}$ until use. Thirteen soil factors (physical, chemical, and biological), for example, $\mathrm{C}: \mathrm{N}$ ratio (organic carbon/total nitrogen), bulk density, and basal respiration, among others, were measured from each sample, as described previously by Gubler et al. [45]. In addition, mean annual temperature (MAT) and mean annual precipitation (MAP) were determined based on yearly data from 1981 to 2015 from MeteoSwiss (http:/ / www.meteoswiss.admin. ch). In total, 15 environmental factors were evaluated in this study (Table S2). 


\subsection{Fungal Isolation and DNA Extraction}

Metarhizium abundance was determined, and single colonies were isolated from each of the three mixed soil samples of the 30 sites. The samples were sieved with a $2 \mathrm{~mm}$ mesh, and soil water content was determined. Then, $5 \mathrm{~g}$ of each homogenized sample was suspended in $25 \mathrm{~mL}$ of sterile distilled water $+0.1 \%$ Tween 80 in a $100 \mathrm{~mL}$ Erlenmeyer flask. Flasks were stirred in a rotatory shaker at $120 \mathrm{rpm}$ at room temperature for $3 \mathrm{~h}$. After $20 \mathrm{~s}$ of sedimentation, $100 \mu \mathrm{L}$ aliquots of the suspension were spread on $90 \mathrm{~mm}$ Petri dishes containing a semi-selective medium (SM) with dodine (Discovery, Leu Gygax AG, Switzerland) as the selective compound [48]. Two replicates were plated per soil sample. Cultures were grown for $15 \mathrm{~d}$ at $24 \pm 1{ }^{\circ} \mathrm{C}$ in the dark and inspected every 2 days. The fungal isolates were classified to the genus level using taxonomic keys [49]. Metarhizium colony forming units (CFU) per g (dry weight) of soil were determined for each plate and means calculated per site. Three sporulating colonies were randomly taken per plate. Conidia of each colony were plated with a dilution smear in a new SM plate, and a monosporic colony was isolated. In total, a maximum of 18 isolates was collected per site. All the fungal isolates obtained were deposited in the culture collection of the Molecular Ecology Group, Agroscope, Zürich, Switzerland.

Monosporic cultures were plated onto sterile filter paper placed on potato dextrose agar (PDA) plates to produce mycelium for DNA extraction. After 4 days of incubation at $24 \pm 1{ }^{\circ} \mathrm{C}$, mycelium was scraped off the filter paper with a sterile scalpel, placed in an Eppendorf tube, and lyophilized for six hours at $-4{ }^{\circ} \mathrm{C}$ using a CentriVap benchtop centrifugal vacuum concentrator (LabConco, Kansas City, MO, USA). Genomic DNA of each isolate was extracted using the NucleopSpin Plant II kit (Machery \& Nagel, Düren, Germany). DNA concentration was determined using a Cary Elipse fluorescence spectrophotometer (Varian, Palo Alto, CA, USA) with a Picogreen ${ }^{\circledR}$ fluorescent nucleic acid stain (Invitrogen, Carlsbad, CA, USA). The DNA extracts were standardized to $5 \mathrm{ng} \mathrm{LL}^{-1}$.

\subsection{Sequence Analysis}

Metarhizium isolates were taxonomically identified to the species level by sequencing the $5^{\prime}$ end of the nuclear translation elongation factor- $1 \alpha\left(5^{\prime}-\mathrm{TEF}-1 \alpha\right)$ and subsequent alignment with reference sequences. The $5^{\prime}$-TEF region was amplified using primers EF1T 5'-ATGGGTAAGGARGACAAGAC-3' [50] and EFjmetaR 5'-TGCTCACGRGTCTGGCCAT CCTT-3' [51]. PCRs were performed in $20 \mu \mathrm{l}$ reaction volumes consisting of $15 \mathrm{ng}$ genomic DNA and $1 x$ Phusion HF buffer containing $7.5 \mathrm{mM} \mathrm{MgCl}_{2}, 0.2 \mathrm{mM}$ dNTPs, $0.2 \mu \mathrm{M}$ of each primer, $3 \%$ dimethyl sulfoxide (DMSO), and $0.2 \mathrm{U}$ of Phusion Hot Start II High-Fidelity DNA polymerase (Thermo Fisher Scientific, Waltham, MA, USA). PCR conditions were: $30 \mathrm{~s}$ denaturation at $98^{\circ} \mathrm{C}$, followed by 38 cycles of $5 \mathrm{~s}$ denaturation at $98^{\circ} \mathrm{C}, 20 \mathrm{~s}$ annealing at $58^{\circ} \mathrm{C}$, and a $1 \mathrm{~min}$ extension at $72{ }^{\circ} \mathrm{C}$. Reactions were completed with a 10 min elongation at $72{ }^{\circ} \mathrm{C}$.

PCR products were cleaned up using the NucleoSpin ${ }^{\circledR}$ Gel and PCR Clean-up kit (Machery \& Nagel, Düren, Germany), following the manufacturer's protocol. Sequencing reactions were performed with primers EF1T and EFjmetaR using the BigDye ${ }^{\mathrm{TM}}$ Terminator v3.1 Cycle Sequencing kit (Applied Biosystems, Foster City, CA, USA) and sequences determined using an ABI PRISM 3130xl genetic analyzer, as described above. Sequences were assembled and corrected using the software DNABaser V.4 (Heracle Biosoft, Pitești, Romania). The obtained sequences were aligned with reference sequences of Metarhizium spp. type isolates for species allocation, as described in Mayerhofer et al. [51]. The sequences of one isolate per multilocus genotype (MLG) are deposited at GeneBank (accession numbers MZ297396 to MZ297417, Appendix A). Reference sequences were downloaded from GenBank, and alignments were performed using the Clustal-W subsequence realignment tool implemented in MEGA X [52]. The maximum likelihood method based on the Kimura 2-parameter model implemented in MEGA X was used to calculate (1000 iterations) and construct a phylogenetic tree [53]. 


\subsection{Multilocus Microsatellite Genotyping}

Fourteen microsatellite markers were used in five primer pair sets, as described by Mayerhofer et al. [54], to assess the genotype of the collected Metarhizium isolates. Multiplex PCRs were performed in $20 \mu \mathrm{L}$ reaction volumes containing $5 \mathrm{ng}$ of genomic DNA, $1 \times$ GoTaq colorless Flexi Buffer, $0.2 \mathrm{mM}$ of each primer (forward primer labeled with FAM, HEX, or NED), $0.2 \mathrm{mM}$ of dNTPs, 3 or $4 \mathrm{mM}$ of $\mathrm{MgCl} 2$ (depending on the multiplex set, [54]) and 0.25 U of GoTaq G2 Flexi DNA Polymerase (Promega, Madison, WI, USA). Cycling conditions included an initial denaturing step of $2 \mathrm{~min}$ at $94{ }^{\circ} \mathrm{C}$, followed by 12 touchdown cycles of $30 \mathrm{~s}$ denaturation at $94{ }^{\circ} \mathrm{C}, 30 \mathrm{~s}$ annealing at $\mathrm{Ta}+12{ }^{\circ} \mathrm{C}$, (with a $1{ }^{\circ} \mathrm{C}$ decrease per cycle), and $40 \mathrm{~s}$ of extension at $72{ }^{\circ} \mathrm{C}$. This was followed by another 22 or 30 cycles [54] of $30 \mathrm{~s}$ denaturation at $94{ }^{\circ} \mathrm{C}, 30 \mathrm{~s}$ at Ta [54], and a $40 \mathrm{~s}$ extension at $72{ }^{\circ} \mathrm{C}$. Reactions were completed with a $15 \mathrm{~min}$ elongation at $72{ }^{\circ} \mathrm{C}$. PCR product sizes (microsatellite allele size) were determined on an ABI 3500 Series genetic analyzer (24 capillaries) using POP-7 polymer (Applied Biosystems, Foster City, CA, USA). GenScan ROX400 (Applied Biosystems) was used as an internal size standard. Data were analyzed using GenMarker V2.4.0 (SoftGenetics, State College, PA, USA) and allele sizes corrected according to fragment sizes of reference strains M. brunneum ARSEF7524 and M. robertsii ARSEF7532.

\subsection{Data Analysis}

Analysis of variance (ANOVA) was used to assess the effect of LUT, site, and soil environmental factors on the abundance of Metarhizium (CFU g ${ }^{-1}$ of soil dry weight), followed by the Tukey-HSD test to assess pairwise differences. Sites with zero Metarhizium spp. abundance were not included in the calculations of differences among LUTs to provide a clear representation of mean fungal abundance where Metarhizium was detected.

Microsatellite marker data analyses were performed with the R package Poppr [55]. Data were clone-corrected, and the number of MLGs calculated. The Shannon-Wiener index (H), [56] and the evenness index (E.5) [57-59] were calculated for each Metarhizium species and LUT based on the occurrence of each MLG.

Differences in the population structure of Metarhizium MLGs among LUTs and species were assessed with overall and pairwise PERMANOVA based on Bray-Curtis (BC) dissimilarity matrices [60] using the function "adonis" within the vegan R package, "pairwise.perm.manova" within the RVAideMemoire R package [61,62], and the BenjaminiHochberg $p$-value correction in R [63]. Effects of soil factors on Metarhizium populations were assessed with overall PERMANOVA tests for each factor individually using the "adonis" function. Principal coordinate analyses (PCoA) were performed based on BC dissimilarity matrices using the "cmdscale" function included in the R core package $[63,64]$. The "envfit" function from the vegan R package was used to plot the correlations between Metarhizium species population structures and the significant soil factors determined in a PCoA ordination.

\section{Results}

\subsection{Abundance of Metarhizium in Soil}

Using a semi-selective medium, the genus Metarhizium was detected at eight of ten arable land sites, at all ten permanent grassland sites, and at four of ten forest sites (Figure 1 and Table S3). LUT significantly $\left(\mathrm{F}_{2,19}=4.30 ; p\right.$-value $\left.=0.0287\right)$ affected the abundance of Metarhizium, determined as CFU g ${ }^{-1}$ soil dry weight. Pairwise tests (Tukey-HSD test, $p$-value $<0.05$ ) revealed significant differences between the site means of grassland (3501.2 $\pm 2254.2 \mathrm{CFU} \mathrm{g}^{-1}$ soil dry weight) and arable land (1199.0 $\pm 1278.5 \mathrm{CFU} \mathrm{g}^{-1}$ soil dry weight) but not between the means of grassland and forest $\left(1620.8 \pm 938.2 \mathrm{CFU} \mathrm{g}^{-1}\right.$ soil dry weight $)$ or arable land and forest. Significant differences $\left(\mathrm{F}_{29,58}=11.63 ; p\right.$-value $\left.<0.0001\right)$ in Metarhizium abundances were also detected among sites (Figure 1 and Table S3), where abundance ranged from 0 to $6362.5 \pm 1467.2 \mathrm{CFU} \mathrm{g}^{-1}$ soil dry weight (mean $\pm \mathrm{SD}$ ). 


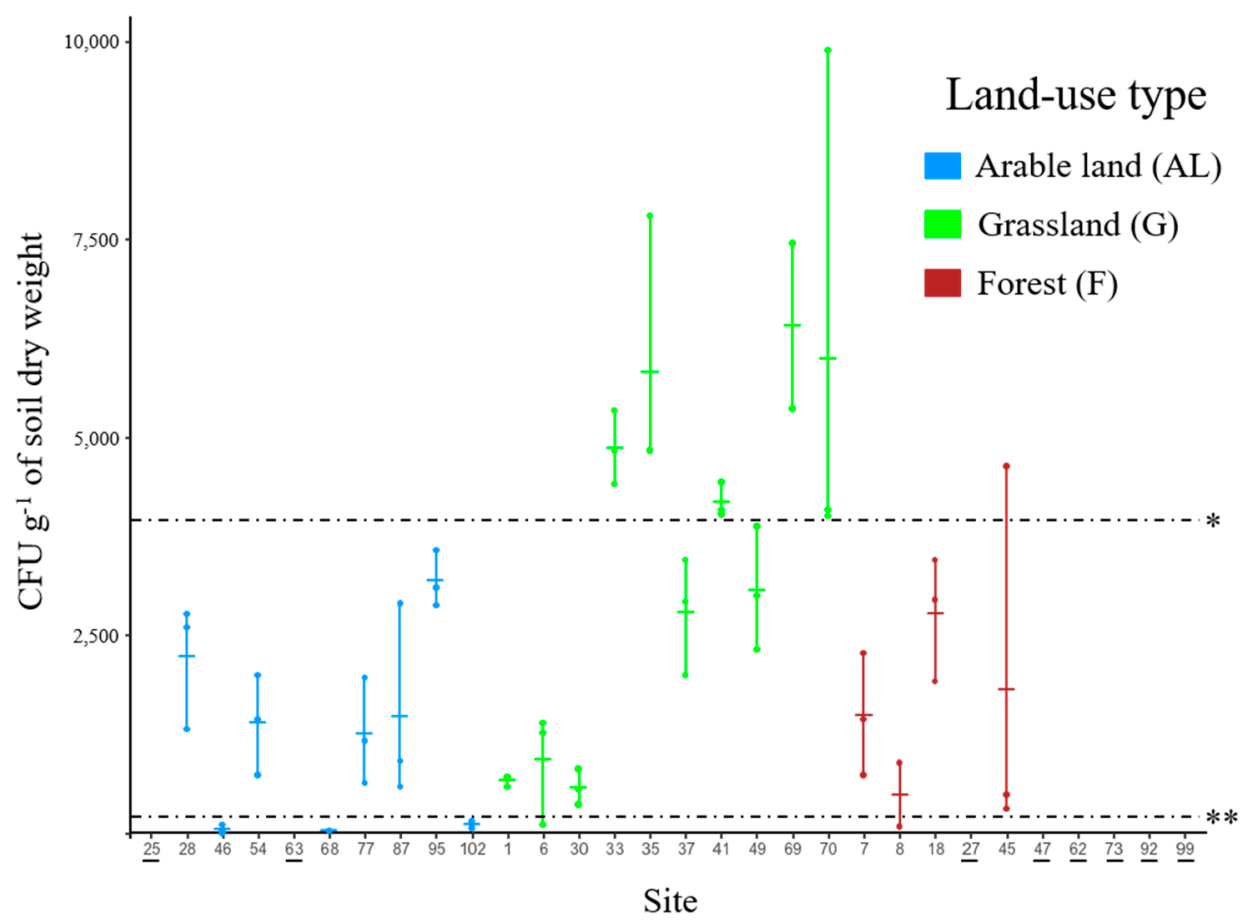

Figure 1. Metarhizium spp. abundance represented as dot plots of colony-forming units (CFU g ${ }^{-1}$ of soil dry weight) for different sites (30 NABObio sites). Dots represent values of $\mathrm{CFU} \mathrm{g}{ }^{-1}$ of soil dry weight in each sample per site, and the intersection represents the mean of CFU g ${ }^{-1}$ of soil dry weight per site. ${ }^{*}$ Dashed line (4000 CFU g ${ }^{-1}$ of soil dry weight) separates the high abundance group from the medium abundance group; ** Dashed line (150 CFU g ${ }^{-1}$ of soil dry weight) separates the medium abundance group from the low abundance group) (Table S3). Site numbers where Metarhizium was not detected are underlined.

Metarhizium abundances at the 30 sites were grouped into three distinct groups, i.e., sites with low abundance (mean abundance $<150 \mathrm{CFU} \mathrm{g}^{-1}$ soil dry weight), medium abundance (mean abundance ranging between 150 and $4000 \mathrm{CFU} \mathrm{g}{ }^{-1}$ soil dry weight), and high abundance (sites with a mean abundance $>4000 \mathrm{CFU} \mathrm{g}{ }^{-1}$ soil dry weight) (Figure 1 and Table S3). Medium Metarhizium abundance was detected at sites of all three LUTs (14 sites), whereas high abundance was only detected in grassland (5 sites). The low abundance group included sites where Metarhizium was detected with a low abundance (3 sites in arable land) as well as sites where Metarhizium was not detected ( 2 sites in arable land, and 6 sites in forest). Arable land was the only LUT that included sites with low abundance as well as sites where the fungus was not detected (5 sites). However, due to missing statistical power, no discrimination of these sites was possible, and they were all combined in the group of low abundance.

\subsection{Effect of Environmental Factors on Metarhizium Abundance Groups}

In total, 15 environmental factors were measured at the 30 sites and assessed for differences among the sites categorized according to the three Metarhizium abundance groups (Table 1 and Tables S4-S7). Two factors, the C:N ratio and mean annual precipitation (MAP), differed significantly among the Metarhizium abundance groups independent of the three LUTs between high and low as well as medium and low abundance groups but not between high and medium abundance groups (Table 1 and Table S4). Within each LUT, different factors were significant between the low, medium, and high abundance groups. In arable land, the six soil factors-altitude, clay, sand, soil skeleton, total carbon, and DNA (proxy for biomass) - differed significantly between the low and medium abundance groups (Table 1 and Table S5). In grassland, only silt significantly differed between high and medium abundance, whereas in forest, altitude, clay, sand, and C:N ratio significantly differed between medium and low Metarhizium abundance (Table 1, Tables S6 and S7). 


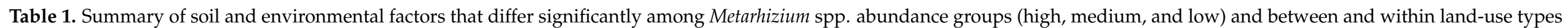
(LUTs).

\begin{tabular}{|c|c|c|c|c|c|c|c|c|c|c|c|c|c|c|c|c|}
\hline \multirow{2}{*}{ LUT } & \multirow{2}{*}{ Factor ${ }^{(1)}$} & \multicolumn{4}{|c|}{ High } & \multicolumn{4}{|c|}{ Medium } & \multicolumn{4}{|c|}{ Low } & \multicolumn{3}{|c|}{ ANOVA } \\
\hline & & Mean & SD & Minimum & Maximum & Mean & SD & Minimum & Maximum & Mean & SD & Minimum & Maximum & F-Value & $p$-Value & Pattern ${ }^{(2)}$ \\
\hline \multirow[b]{2}{*}{ All LUT } & C:N ratio & 9.6 & 0.9 & 8.9 & 10.0 & 11.1 & 3.1 & 8.0 & 17.7 & 14.2 & 5.5 & 8.6 & 27.0 & 8.72 & 0.0004 & $\mathrm{H}=\mathrm{M} \neq \mathrm{L}$ \\
\hline & MAP [mm] & 1496.2 & 321.0 & 1090.0 & 1910.0 & 1342.4 & 363.2 & 962.0 & 2140.0 & 1116.7 & 368.5 & 528.0 & 1838.0 & 6.77 & 0.0019 & $\mathrm{H}=\mathrm{M} \neq \mathrm{L}$ \\
\hline \multirow{6}{*}{$\begin{array}{l}\text { Arable } \\
\text { land }\end{array}$} & Altitude [masl] & - (3) & - & - & - & 549.4 & 167.9 & 336.0 & 830.0 & 449.6 & 55.6 & 379.0 & 545.0 & 4.78 & 0.0374 & $\mathrm{M} \neq \mathrm{L}$ \\
\hline & Clay [\% sdw] & - & - & - & - & 17.6 & 4.6 & 11.5 & 23.8 & 32.5 & 19.1 & 5.8 & 59.0 & 8.69 & 0.0064 & $\mathrm{M} \neq \mathrm{L}$ \\
\hline & Sand [\% sdw] & - & - & - & - & 42.2 & 9.8 & 31.0 & 54.0 & 22.4 & 11.4 & 11.0 & 36.1 & 26.15 & $<0.0001$ & $\mathrm{M} \neq \mathrm{L}$ \\
\hline & $\begin{array}{l}\text { Soil skeleton [\% } \\
\text { sv] }\end{array}$ & - & - & - & - & 4.0 & 0.8 & 3.1 & 4.9 & 0.7 & 0.8 & 0.0 & 2.0 & 135.85 & $<0.0001$ & $\mathrm{M} \neq \mathrm{L}$ \\
\hline & $\begin{array}{c}\text { Total Carbon [\% } \\
\text { sdw] }\end{array}$ & - & - & - & - & 2.0 & 0.7 & 1.1 & 3.2 & 2.8 & 0.9 & 1.8 & 4.3 & 8.55 & 0.0068 & $\mathrm{M} \neq \mathrm{L}$ \\
\hline & $\begin{array}{l}\text { DNA [ } \mu \mathrm{g} / \mathrm{mg} \\
\text { sdw] }\end{array}$ & - & - & - & - & 25.5 & 9.1 & 14.0 & 45.0 & 17.9 & 3.8 & 13.0 & 26.0 & 8.85 & 0.006 & $\mathrm{M} \neq \mathrm{L}$ \\
\hline Grassland & Silt [\% sdw] & 42.3 & 8.4 & 34.3 & 55.0 & 35.6 & 7.9 & 27.0 & 49.9 & & - & - & - & 5.10 & 0.0319 & $\mathrm{H} \neq \mathrm{M}$ \\
\hline \multirow{4}{*}{ Forest } & Altitude [masl] & - & - & - & - & 745.3 & 269.9 & 525.00 & 1180.0 & 1115.8 & 408.7 & 505.0 & 1655.0 & 7.60 & 0.0101 & $\mathrm{M} \neq \mathrm{L}$ \\
\hline & Clay [\% sdw] & - & - & - & - & 31.1 & 9.1 & 18.8 & 42.0 & 17.8 & 8.3 & 7.0 & 30.5 & 17.30 & 0.0003 & $\mathrm{M} \neq \mathrm{L}$ \\
\hline & Sand [\% sdw] & - & - & - & - & 31.1 & 8.7 & 18.0 & 39.0 & 47.2 & 21.0 & 17.5 & 71.0 & 6.35 & 0.0177 & $\mathrm{M} \neq \mathrm{L}$ \\
\hline & C:N ratio & - & - & - & - & 15.5 & 2.2 & 12.0 & 17.7 & 18.2 & 4.3 & 13.7 & 27.0 & 4.25 & 0.0488 & $M \neq L$ \\
\hline
\end{tabular}

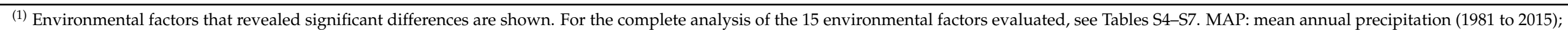

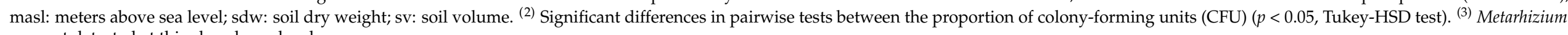
was not detected at this abundance level. 


\subsection{Metarhizium Species Occurrence and Genetic Diversity}

In total, 349 isolates were collected from the 22 sites at which Metarhizium was detected and, based on sequence analyses of the $5^{\prime}$ end of nuclear translation elongation factor- $1 \alpha$ ( $5^{\prime}$-TEF-1 $\alpha$ ), assigned to three Metarhizium species: M. brunneum (259 isolates), M. robertsii (80 isolates), and M. guizhouense (10 isolates) (Table 2 and Table S1). M. brunneum was present in all three LUTs ( 7 arable land sites, 10 grassland sites, 4 forest sites), whereas $M$. robertsii and $M$. guizhouense were present in arable land (M. robertsii 6 sites, M. guizhouense 1 site) and grassland only (M. robertsii 4 sites, M. guizhouense 2 sites; Table 2 and Figure 2). The proportion of M. brunneum and M. robertsii isolates was similar in the low (61\% and $39 \%$ ) and medium (56\% and 40\%) abundance groups in arable land and the high (57\% and $36 \%$ ) abundance group in grassland (Figure 2). In contrast, in the medium abundance group in grassland, the portion of M. brunneum isolates was higher, i.e., M. brunneum $94 \%$ and M. robertsii 5\% (Figure 2). M. guizhouense was detected in the medium abundance group in arable land $(4 \%)$ and grassland $(1 \%)$ and the high abundance group in grassland (7\%) (Figure 2).

Table 2. Numbers of isolates, multilocus genotypes, and genotype diversity among the three Metarhizium species-M. brunneum, M. robertsii, and M. guizhouense-for three different LUTs: arable land, grassland, and forest.

\begin{tabular}{cccccccccccccccc}
\hline & \multicolumn{3}{c}{ Metarhizium spp. } & \multicolumn{4}{c}{ M. brunneum } & \multicolumn{4}{c}{ M. robertsii } & \multicolumn{4}{c}{ M. guizhouense } \\
\hline Land-Use Type & N & MLG & N & MLG & H & E.5 & N & MLG & H & E.5 & N & MLG & H & E.5 \\
\hline Arable land & 115 & 10 & 66 & 4 & 0.99 & 0.75 & 46 & 5 & 1.09 & 0.60 & 3 & 1 & - & - \\
Grassland & 171 & 12 & 130 & 7 & 1.33 & 0.75 & 34 & 3 & 0.70 & 0.74 & 7 & 2 & - & - \\
Forest & 63 & 4 & 63 & 4 & 0.96 & 0.80 & - & - & & - & - & - & - \\
Total & 349 & 22 & 259 & 13 & 1.84 & 0.72 & 80 & 6 & 1.17 & 0.74 & 10 & 3 & - & - \\
\hline
\end{tabular}

$\mathrm{N}$ : total number of isolates; MLG: number of unique multilocus genotypes; H: Shannon-Wiener index; E.5: evenness.

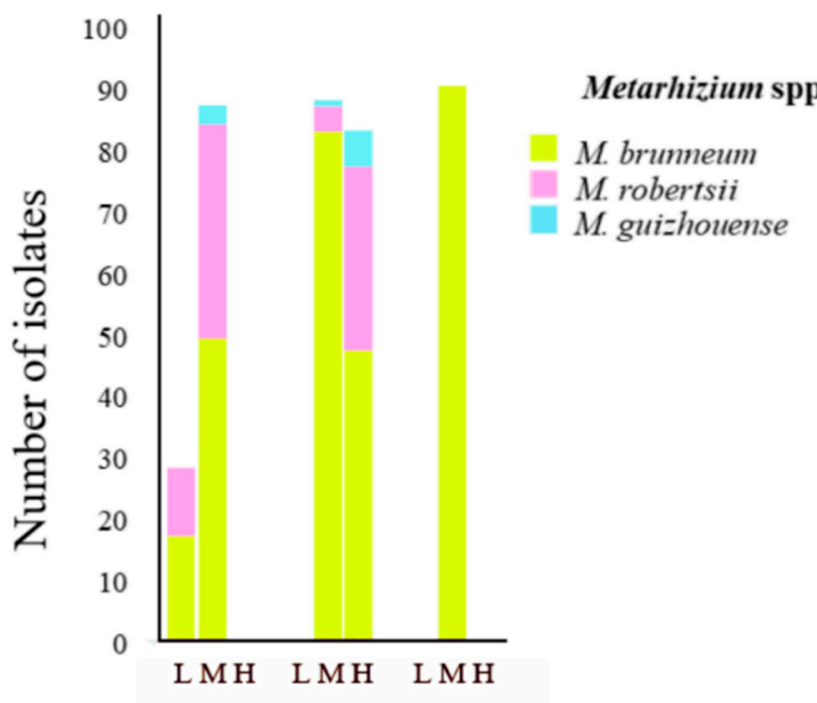

AL $\quad G \quad F$

Figure 2. Number of isolates recovered for the three species identified (M. brunneum, M. robertsii, and M. guizhouense) in each of the three land-use types_-arable land (AL), grassland (G), and forest (F)separated according to the three abundance groups, low (L), medium (M), and high (H) (see Figure 1).

Genotyping of the isolates based on microsatellite analyses revealed 22 different MLGs among the 349 isolates: 13 MLGs for M. brunneum, 6 MLGs for M. robertsii, and 3 MLGs for M. guizhouense, revealing that these microsatellite-based MLGs were species-specific (Figure 3 and Table 2). Overall, the number of detected MLGs was similar in arable land and grassland, while it was 2.5 to 3 times lower in forest. For M. brunneum, the number of 
MLGs was higher in grassland compared to arable land and forest, whereas for $M$ robertsii, the number of MLGs was higher in arable land. Shannon-Wiener genetic diversity $(\mathrm{H})$ for M. brunneum was highest in permanent grassland, followed by arable land and forest, while for M. robertsii, diversity was higher in arable land and lower in grassland (Table 2). In contrast, the evenness (E.5) of M. brunneum was higher in forest compared to grassland and arable land, and the evenness of $M$. robertsii was higher in grassland compared to arable land (Table 2). Due to the low number of M. guizhouense isolates identified, diversity indices for this species were not calculated.

Sample size
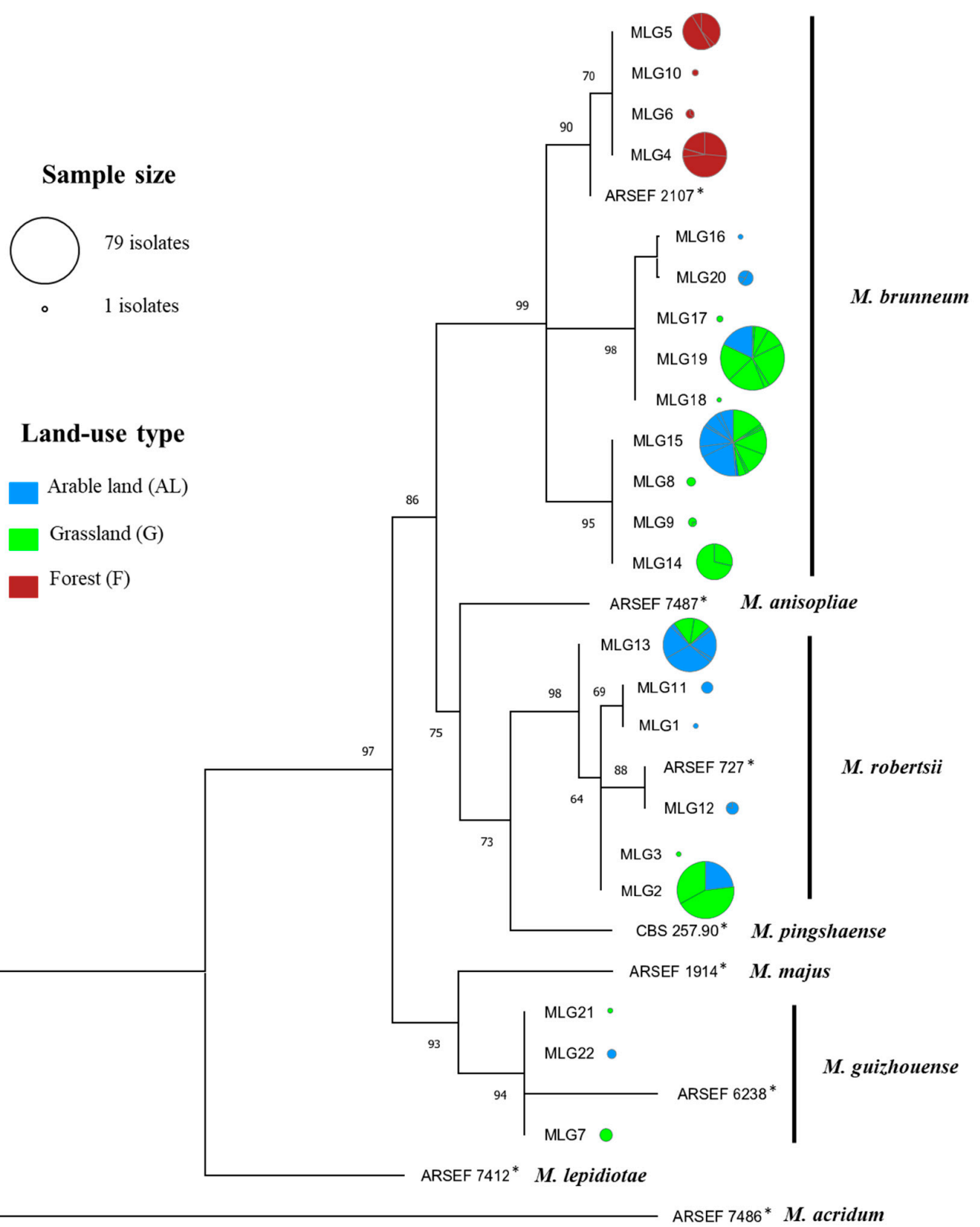

ARSEF $7486^{*}$ M. acridum

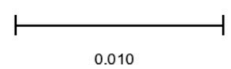

Figure 3. Maximum likelihood phylogenetic tree based on the alignment of $5^{\prime}$-TEF- $1 \alpha$ sequences representing each of the 22 different multilocus genotypes (MLG). Bootstrap values $>60 \%$, calculated with 1000 replicates, are shown. The bar scale indicates 0.01 changes per nucleotide. Each circle represents a unique MLG, and circle size indicates the number of isolates recovered. Colors within the circles represent the fraction of clones obtained per land-use type, and vertex size represents the fraction of clones isolated at sites where the MLG was detected. 
In total, 18 of the 22 MLGs were specific to one of the three LUTs. Six MLGs were specific to arable land (two M. brunneum, three M. robertsii, one $M$. guizhouense), eight to permanent grassland (five M. brunneum, one M. robertsii, two M. guizhouense), and four to forest, which clustered separately within M. brunneum in the $5^{\prime}$-TEF- $1 \alpha$-based phylogenetic tree (Figure 3). None of the MLGs were detected in all three LUTs, while the four most abundant MLGs, i.e., two M. brunneum (15 and 19) and two M. robertsii MLGs (2 and 13), were present in arable land and grassland and represented $63.61 \%$ of all Metarhizium isolates collected (Figure 3). The four forest-specific MLGs represented $18.05 \%$ of all Metarhizium spp. isolates investigated. The abundance of individual MLGs did not correlate with affiliation to particular Metarhizium abundance groups, e.g., M. brunneum MLG15 and $M$. robertsii MLG 13 were present in the low, medium, and high abundance groups in different sites (data not shown). Eleven MLGs (five M. brunneum, three M. robertsii, and three $M$. guizhouense) were isolated from single sites only (Figure 3). In contrast, MLG 15 comprised isolates from 15 different sites. Two MLGs (MLG 4 and 5) of the four forest-specific MLGs included isolates from all the four sites and two included isolates from two sites (MLG 6) and one (MLG 10) site where M. brunneum was detected (Figure 3).

\subsection{Land-Use Type Effect on Metarhizium Populations}

Overall, PERMANOVAs indicated that the three LUTs significantly explained the variation in $M$. brunneum population structures $\left(\mathrm{R}^{2}=0.37\right.$; pseudo-F $=5.36$; $p$-value $\left.=0.0001\right)$ (Table 3). PCoA explained $47.00 \%$ of the observed variation among M. brunneum populations, i.e., $24.40 \%$ of the variation in the first axis, separating forest populations from arable land and grassland populations and $22.60 \%$ of the variation in the second axis, differentiating between arable land and grassland populations (Figure 4A). Pairwise PERMANOVA tests among the three LUTs revealed significant differences between M. brunneum populations from forest and arable land $(p$-value $=0.003)$, between forest and grassland $(p$-value $=0.003)$, but not between grassland and arable land ( $p$-value $=0.05)$. Overall, PERMANOVA indicated that the LUT (arable land, grassland) did not significantly explain the variation among $M$. robertsii population structures $(p$-value $=0.466)$ (Table 3$)$. PCoA explained $70.40 \%$ of the observed variation among $M$. robertsii arable land and grassland populations, i.e., $52.00 \%$ of the variation in the first axis and $28.40 \%$ of the variation in the second axis (Figure 4B). Variations among M. guizhouense populations were not evaluated further due to the low number of isolates (10) and genotypes (3 MLGs) detected.

Table 3. Overall permutational multivariate analysis of variance (PERMANOVA) for individual soil and environmental factors, which significantly affect M. brunneum and M. robertsii population structures among and within each land-use type. Analyses were based on Bray-Curtis distances.

\begin{tabular}{|c|c|c|c|c|c|c|c|c|}
\hline & \multicolumn{5}{|c|}{ M. brunneum } & \multicolumn{3}{|c|}{ M. robertsii } \\
\hline & $\begin{array}{l}\text { Among } \\
3 \text { LUTs }\end{array}$ & $\begin{array}{l}\text { Grassland- } \\
\text { Arable } \\
\text { Land }\end{array}$ & $\begin{array}{c}\text { Arable } \\
\text { Land }\end{array}$ & Grassland & Forest & $\begin{array}{l}\text { Between } 2 \\
\text { LUTs }\end{array}$ & $\begin{array}{c}\text { Arable } \\
\text { Land }\end{array}$ & Grassland \\
\hline Variable & $\begin{array}{c}p \text {-Value } \\
\left(\mathrm{R}^{2}\right)\end{array}$ & $\begin{array}{c}p \text {-Value } \\
\left(\mathrm{R}^{2}\right)\end{array}$ & $\begin{array}{c}p \text {-Value } \\
\left(\mathrm{R}^{2}\right)\end{array}$ & $\begin{array}{c}p \text {-Value } \\
\left(\mathrm{R}^{2}\right)\end{array}$ & $\begin{array}{c}p \text {-Value } \\
\left(\mathrm{R}^{2}\right)\end{array}$ & $\begin{array}{c}p \text {-Value } \\
\left(\mathrm{R}^{2}\right)\end{array}$ & $\begin{array}{c}p \text {-Value } \\
\left(\mathbf{R}^{2}\right)\end{array}$ & $\begin{array}{c}p \text {-Value } \\
\left(\mathrm{R}^{2}\right)\end{array}$ \\
\hline Land-use type & $0.0001(37 \%)$ & 0.0513 & - & - & - & 0.4665 & - & - \\
\hline C:N ratio & $0.0001(25 \%)$ & 0.1149 & 0.9821 & $0.0074(26 \%)$ & 0.2083 & 0.5366 & 0.4599 & 0.8333 \\
\hline Basal respiration & $0.0071(13 \%)$ & 0.0928 & 0.3016 & 0.7186 & 0.1667 & 0.1327 & 0.4595 & 0.6668 \\
\hline Organic Carbon & $0.0039(12 \%)$ & 0.0861 & 0.5563 & 0.6421 & 0.2083 & 0.2562 & 0.6476 & 0.8333 \\
\hline Total Carbon & $0.0055(11 \%)$ & 0.1657 & 0.5891 & 0.6488 & 0.2083 & 0.1403 & 0.3230 & 0.8333 \\
\hline Bulk density & $0.0055(13 \%)$ & 0.2375 & 0.5190 & 0.0893 & 0.2500 & 0.1333 & 0.6103 & 0.1667 \\
\hline Soil skeleton & 0.5821 & 0.4503 & 0.8032 & 0.5633 & 0.8333 & $0.0098(33 \%)$ & 0.3008 & 0.3333 \\
\hline
\end{tabular}

$\mathrm{R}^{2}$ values are shown in parentheses when significant (in bold). For the complete analysis, see Tables S8-S15. 


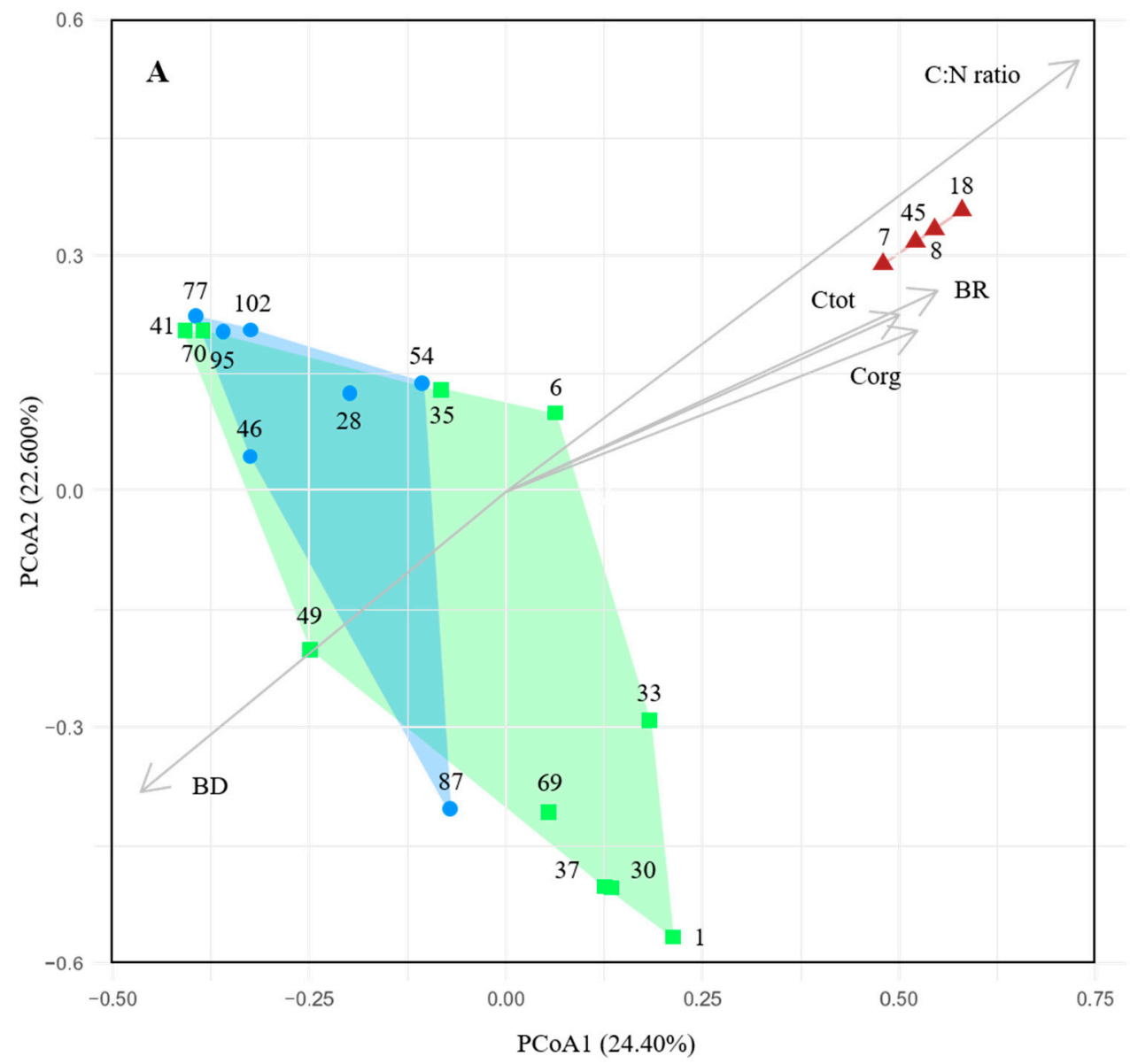

\section{Land-use type}

- Arable land

- Grassland

- Forest

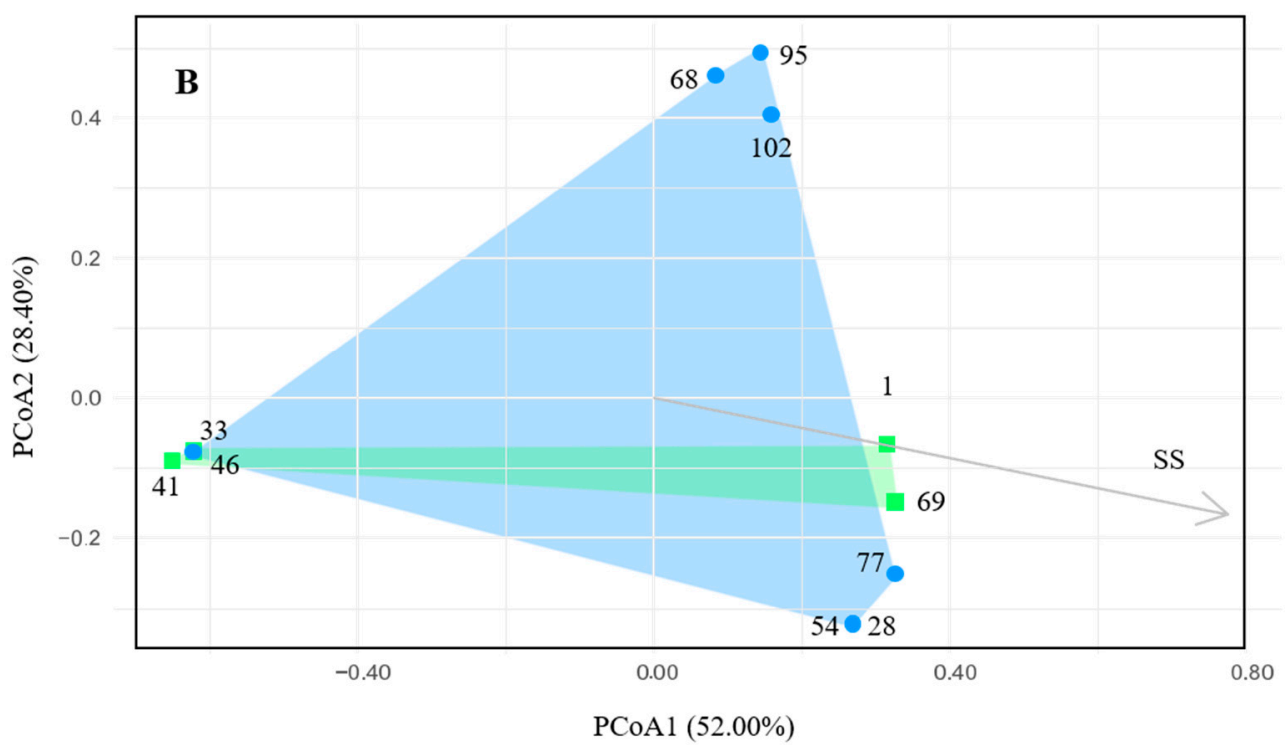

Figure 4. Principal coordinate analysis (PCoA) based on a Bray-Curtis dissimilarity matrix showing differences between (A) M. brunneum and (B) M. robertsii populations at the sites of three land-use types: arable land, grassland, and forest. Circles (arable land), squares (grassland), and triangles (forest) represent M. brunneum or M. robertsii populations at the different sites (site numbers indicated). Convex hulls enclose samples of the same land-use type. The percentage of variation explained by the plotted principal coordinates is indicated on the axes. Vectors represent the best fitted and explained environmental factors, and vector lengths represent the strength of correlation. $\mathrm{C}: \mathrm{N}$ ratio: ratio of organic carbon and total nitrogen; Ctot: total carbon; Corg: organic carbon; BR: basal respiration; BD: bulk density; SS: soil skeleton. 


\subsection{Effect of Environmental Factors on Metarhizium Populations}

PERMANOVA revealed that 5 of the 15 environmental factors significantly explained the variation of M. brunneum population structures among the three LUTs (Table 3 and Figure $4 \mathrm{~A})$. Most variation was explained by the factor C:N ratio (25\%), whereas basal respiration, total carbon, organic carbon, and bulk density explained the variation in the same range of $11 \%$ to $13 \%$. Soil skeleton was the only factor that significantly explained the variation among $M$. robertsii populations from arable land and grassland (Table 3 and Figure 4B). Except for the factor C:N ratio, which significantly explained the variation of $M$. brunneum populations among grassland sites, no other environmental factor significantly explained the variation of M. brunneum or M. robertsii populations within arable land, grassland, or forest.

\section{Discussion}

Identification of the factors that drive population structure and development of insect pathogenic fungi such as Metarhizium spp. is a fundamental requirement to exploit their potential in biological control. The results presented in this study emphasize the effect and influence of particular LUTs on Metarhizium abundance and population structures and indicate the complexity of the factors involved. Populations at the 30 sites investigated were composed of the three species $M$. brunneum, M. robertsii, and M. guizhouense, of which M. brunneum (with $74 \%$ of isolates recovered) was the most abundant and genotypically diverse species and M. guizhouense (with 3\%) the least abundant of all isolates collected. Distinct differences in Metarhizium population structures were detected between forest and the two unforested LUTs, arable land and grassland, revealed by the finding that $M$. robertsii and M. guizhouense were not detected in forest and M. brunneum was represented by four forest-specific genotypes. Although population structures did not differ between the two unforested LUTs, Metarhizium spp. abundance was significantly higher in grassland compared to arable land.

\subsection{M. brunneum Populations in Forested vs. Unforested LUTs}

The forest sites of the NABO network provided characteristic soil environmental conditions, with reduced exposure to sunlight, low soil bulk density, and high basal respiration, as well as high carbon content and C:N ratio (Table S16). These physical, chemical, and biological factors were correlated with $M$. brunneum population variation among the 10 forest sites and 20 arable land or grassland sites, indicating their importance to the structure of Metarhizium populations. The difference between M. brunneum populations in forested and unforested sites was explained particularly by the soil factor C:N ratio, which was also the only factor that significantly explained M. brunneum population variation within one LUT, i.e., among grassland sites. The C:N ratio also differed significantly between low and medium Metarhizium abundance groups among all LUTs and among forest sites (Table

1). Our results suggest that Metarhizium abundance and species and genotype diversity tend to be higher when the C:N ratio is medium-low (Tables 1-3). In contrast to our results, Uzman et al. [43] reported enhanced Metarhizium spp. abundance with increasing $\mathrm{C}: \mathrm{N}$ ratios in vineyard soils, and Clifton et al. [22] showed a negative correlation between Metarhizium spp. abundance and $\mathrm{N}$ concentration, a factor indirectly related to C:N ratios in soils of conventional and organically farmed fields. The latter authors hypothesized that this effect may be due to a stimulation of certain microorganisms that exploit elevated $\mathrm{N}$ concentrations and, subsequently, may outcompete Metarhizium spp. In vitro studies have demonstrated that the proportion of $\mathrm{C}$ and $\mathrm{N}$ in culture media considerably affects the production of biomass, conidia, and insecticidal molecules as well as the virulence of Metarhizium spp. [65-67]. These laboratory experiments were performed with a variety of $\mathrm{C}$ and $\mathrm{N}$ sources in artificial media, and, therefore, it remains unresolved as to what extent these findings may apply to soil. 


\subsection{Metarhizium Populations in Arable Land vs. Grassland}

Although M. brunneum and M. robertsii population structures in arable land and grassland were not significantly different, we detected significant differences between the two LUTs in overall abundance as well as the abundance group associations of the sites. Mean $\mathrm{CFU} \mathrm{g}{ }^{-1}$ values in the grassland sites were approximately twice as high as the values in arable land. In addition, in grassland, Metarhizium was present with high or medium abundance at all the sites, whereas in arable land, Metarhizium was present with medium and low abundances and not even detected at two sites. Interestingly, at the forest sites, the fungus was detected at only 4 out of 10 sites, all belonging to the medium abundance group. The mean abundance was similar to the one detected in arable land when considering only sites where the fungus was detected. MAP is a factor that characterizes the different sites in terms of precipitation. It has been shown to correlate with soil humidity [68], which is well recognized as a critical factor for fungal abundance and the colonization of soil (e.g., [69]). The fact that the MAP values in our study were significantly higher at sites with medium abundance compared to sites with low Metarhizium abundance indicates that the MAP in our system also affected soil humidity, which, in turn, induced Metarhizium growth. However, we did not find any within the LUT correlation of MAP with Metarhizium abundance. Other factors that were significantly correlated with Metarhizium abundance groups within different LUTs, e.g., altitude, clay, or sand, did not reveal significant differences among LUTs, which may indicate that these factors characterize geographical differences among the sites rather than LUTs.

Direct comparisons of different studies are generally difficult to perform due to differences in isolation techniques, sampling schemes, habitat definitions, geographic and/or climatic zones. Additional local factors such as climat, vegetation, and geographic history may increase the complexity of interacting factors. However, in accordance with our results, Keller et al. [27] also reported a higher abundance of Metarhizium spp. ( $M$. anisopliae complex) in meadows (semi-managed unforested land) compared to agricultural land in Switzerland. Furthermore, Schneider et al. [28] detected higher Metarhizium clade1 (M. anisopliae species complex) ITS copy numbers using real-time PCR in permanent grasslands and improved field margins compared to arable land. Such unforested land types do not receive pesticide treatments and are not subject to soil disturbances such as tillage. A number of studies have shown that soil receiving reduced or no soil management, including organically farmed soils, will allow a higher abundance of Metarhizium or entomopathogenic fungi in general $[22,29,30,70,71]$. Interestingly, it has been shown that, in contrast, tillage may also increase Metarhizium spp. abundance [20,21]. The authors of these studies have argued that tillage may disperse Metarhizium propagules, resulting in a more homogenous distribution of the fungus in the soil and, thus, increasing its overall abundance.

\subsection{Association Metarhizium Species and Genotypes to LUTS}

We observed different affinities of M. brunneum, M. robertsii, and M. guizhouense to the three LUTs. While M. brunneum was detected in all LUTs (73.3\% of the sites) and was the dominant species at 16 out of 22 sites as well as in the three abundance groups, $M$. robertsii and M. guizhouense were detected in arable land and grassland only ( $36.6 \%$ and $10.0 \%$ of the sites). However, whereas $M$. robetsii was detected within low and medium abundance groups in arable land and low and high abundance groups in grassland, M. guizhouense was detected only in the medium abundance group in arable land and medium and high abundance groups in grassland. The M. brunneum genotypes detected at the forest sites were specific to forests and clustered separately from the genotypes detected at the arable land or grassland sites. In addition, certain MLGs were particularly dominant and present at multiple sites across the country (MLG2, MLG13, MLG 15, MLG 19). Species affinity to particular sites, regions, or habitats and the dominance of particular genotypes have been reported previously on a field level [21,36] as well as on a regional level $[38,72,73]$. Plant species composition characteristically differs between habitats or LUTs such as agricultural 
land, grassland, and forest. Previous studies have provided evidence that Metarhizium spp. can form stable associations with certain plant species [32,74], and that crop type may affect Metarhizium spp. diversity and abundance [21,31]. For instance, CabreraMora et al. [31] predominantly isolated M. brunneum from bean-cultivated soil and $M$. robertsii from maize-cultivated soil, and Kepler et al. [21] detected higher Metarhizium abundance in soybean fields versus cornfields. Furthermore, it is well documented that arthropod populations vary substantially among LUTs [75]. Species associated with forests, for instance, bark beetles (Scolytus spp.), may not be present in unforested habitats, and pest species like wireworm spp. or western corn rootworm are linked to certain crop plants. The population structure of arthropod pathogenic fungi such as Metarhizium, which includes species and genotypes with diverse host ranges (from narrow to broad), is likely affected and shaped by arthropod populations (host selection). Furthermore, it has been observed that small soil arthropods, such as collembolans and mites, may be involved in the dispersal of fungal propagules in the soil, which may also have an effect on fungal population development [76]. The data reported here and observations made by others strongly indicate the importance of plant and arthropod populations in particular habitats and LUTs as the driving force for shaping the population structure of entomopathogenic fungi such as Metarhizium spp.

\section{Conclusions}

The 30 sites investigated in this study represent 3 well-defined and characterized habitat types in Switzerland. Being part of the Swiss soil-monitoring network (NABO), the sites have been cultivated, maintained, and monitored for the last three decades according to the same procedures and protocols, and therefore, represent well-established habitats. This long-term experimental system allowed us to unravel the significant impacts of the different LUTs on Metarhizium abundance, species diversity, and their population structures and indicated the complexity of environmental factors involved. With the detection of LUT-specific MLGs of M. brunneum and the absence of M. robertsii and M. guizhouense at forest sites, the study has emphasized the significant impact of forested versus unforested LUTs on Metarhizium population structures. These results will provide an important base to further explore other factors that may shape Metarhizium populations, which, for instance, may include the effects of plant populations as well as the diversity of arthropod populations present in the soil. Information compiled from such system approaches will reinforce the criteria for the selection of LUT-adapted fungal strains for evaluation as biological control agents. Future biological control strategies may not only include strains that are most virulent to particular pest insects but also those adapted to specific habitats, crops, or even sites. Such strategies may also include the manipulation of LUTs, for instance, by the cultivation of plant species that interact with these beneficial fungal species and support their growth, even in the occasional absence of a particular pest.

Supplementary Materials: The following are available online at https: / www.mdpi.com/article / 10.3390/microorganisms9071380/s1, Figure S1: Georeferenced sampling sites of the three land-use types, comprising 10 arable land sites, 10 grassland site, and 10 forest sites, Table S1: Summary information of samples, Table S2: Site metadata information: description of environmental factors of each site, Table S3: Means and ANOVA of Metarhizium spp. colony-forming units (CFU) $\mathrm{g}^{-1}$ of soil dry weight in each site. Affiliation of each site to one of the three abundance groups based on mean CFU is indicated, Table S4: Summary of 15 soil and environmental factors affecting the abundance groups observed among the 30 sites: high, medium, and low Metarhizium abundance (CFU g ${ }^{-1}$ of soil dry weight), Table S5: Summary of 15 soil and environmental factors affecting two Metarhizium abundance (CFU g ${ }^{-1}$ of soil dry weight) groups, medium and low, in arable land, Table S6: Summary of 15 soil and environmental factors affecting two Metarhizium abundance (CFU g ${ }^{-1}$ of soil dry weight) groups, high and medium, in grassland, Table S7: Summary of 15 soil and environmental factors affecting two Metarhizium abundance (CFU g ${ }^{-s 1}$ of soil dry weight) groups, medium and low, in forest, Table S8: Overall permutational multivariate analysis of variance (PERMANOVA) for individual soil and environmental factors that significantly affect $M$. brunneum population structures among 
three land-use types. Analyses were based on Bray-Curtis distances, Table S9: Overall permutational multivariate analysis of variance (PERMANOVA) for individual soil and environmental factors that significantly affect $M$. brunneum population structures in arable land and grassland. Analyses were based on Bray-Curtis distances, Table S10: Overall permutational multivariate analysis of variance (PERMANOVA) for individual soil and environmental factors that significantly affect $M$. brunneum population structures within arable land. Analyses were based on Bray-Curtis distances, Table S11: Overall permutational multivariate analysis of variance (PERMANOVA) for individual soil and environmental factors that significantly affect M. brunneum population structures within grassland. Analyses were based on Bray-Curtis distances, Table S12: Overall permutational multivariate analysis of variance (PERMANOVA) for individual soil and environmental factors that significantly affect $M$. brunneum population structures within forest sites. Analyses were based on Bray-Curtis distances, Table S13: Overall permutational multivariate analysis of variance (PERMANOVA) for individual soil and environmental factors that significantly affect $M$. robertsii population structures among three land-use types. Analyses were based on Bray-Curtis distances, Table S14: Overall permutational multivariate analysis of variance (PERMANOVA) for individual soil and environmental factors that significantly affect $M$. robertsii population structures within arable land. Analyses were based on BrayCurtis distances, Table S15: Overall permutational multivariate analysis of variance (PERMANOVA) for individual soil and environmental factors that significantly affect $M$. robertsii population structure within grassland. Analyses were based on Bray-Curtis distances, Table S16: Summary of environmental factors at the ten sites of each land-use type.

Author Contributions: Wrote the paper: M.F.-B. and J.E.; reviewed paper: M.F.-B., J.E., F.G., J.M., F.W., and A.H.; analyzed data: M.F.-B., F.G., and J.M.; performed experiments: M.F.-B., A.H., and J.E.; critically discussed results: M.F.-B., F.G., J.M., J.E., and F.W.; designed experiments: J.E. and F.W.; supervision: J.E.; funding acquisition: J.E. and M.F.-B. All authors have read and agreed to the published version of the manuscript.

Funding: This project has received funding from the European Union's Horizon 2020 research and innovation program under Marie Skłodowska-Curie grant agreement no. 794526.

Data Availability Statement: All additional data can be obtained from the corresponding author upon reasonable request.

Acknowledgments: We wish to thank Tabea Koch, Sonja Reinhard, and Stephanie Pfister for technical help and the NABO team at Agroscope for the collection of soil samples.

Conflicts of Interest: The authors declare no conflict of interest.

\section{Appendix A}

Table A1. GenBank accession numbers of the EF1a sequences used to construct the phylogenetic tree in Figure 3 of one representative isolate per MLG.

\begin{tabular}{cccc}
\hline $\begin{array}{c}\text { GeneBank } \\
\text { Accession Number }\end{array}$ & Isolate & MLG & Species \\
\hline MZ297396 & $95-\mathrm{III}-2$ & MLG12 & M. robertsii \\
MZ297397 & $87-\mathrm{III}-4$ & MLG19 & M. brunneum \\
MZ297398 & $77-\mathrm{III}-5$ & MLG16 & M. brunneum \\
MZ297399 & $77-\mathrm{I}-1$ & MLG20 & M. brunneum \\
MZ297400 & $70-\mathrm{III}-1$ & MLG15 & M. brunneum \\
MZ297401 & $70-\mathrm{II}-1$ & MLG7 & M. guizhouense \\
MZ297402 & $54-\mathrm{I}-4$ & MLG1 & M. robertsii \\
MZ297403 & $45-\mathrm{III}-6$ & MLG4 & M. brunneum \\
MZ297404 & $45-\mathrm{I}-1$ & MLG6 & M. brunneum \\
MZ297405 & $35-\mathrm{III}-3$ & MLG8 & M. brunneum \\
MZ297406 & 35-II-5 & MLG9 & M. brunneum \\
\hline
\end{tabular}


Table A1. Cont.

\begin{tabular}{cccc}
\hline $\begin{array}{c}\text { GeneBank } \\
\text { Accession Number }\end{array}$ & Isolate & MLG & Species \\
\hline MZ297407 & 35-I-6 & MLG17 & M. brunneum \\
MZ297408 & $33-\mathrm{I}-6$ & MLG2 & M. robertsii \\
MZ297409 & $33-\mathrm{I}-5$ & MLG3 & M. robertsii \\
MZ297410 & $30-\mathrm{II}-6$ & MLG21 & M. guizhouense \\
MZ297411 & $30-\mathrm{I}-3$ & MLG18 & M. brunneum \\
MZ297412 & $28-\mathrm{II}-2$ & MLG22 & M. guizhouense \\
MZ297413 & $28-\mathrm{I}-1$ & MLG11 & M. robertsii \\
MZ297414 & $18-\mathrm{III}-3$ & MLG5 & M. brunneum \\
MZ297415 & $7-\mathrm{III}-6$ & MLG10 & M. brunneum \\
MZ297416 & $6-\mathrm{I}-2$ & MLG14 & M. brunneum \\
MZ297417 & $1-\mathrm{III}-4$ & MLG13 & M. robertsii \\
\hline
\end{tabular}

\section{References}

1. Brunner-Mendoza, C.; Reyes-Montes, M.R.; Moonjely, S.; Bidochka, M.J.; Toriello, C. A review on the genus Metarhizium as an entomopathogenic microbial biocontrol agent with emphasis on its use and utility in Mexico. Biocontrol. Sci. Technol. 2019, 29, 83-102. [CrossRef]

2. Goettel, M.S.; Eilenberg, J.; Glare, T. Entomopathogenic fungi and their role in regulation of insect populations. In Comprehensive Molecular Insect Science; Gilbert, L.I., Gill, S.S., Eds.; Elsevier: Boston, MA, USA, 2005; pp. 361-406.

3. Lawo, N.C.; Mahon, R.J.; Milner, R.J.; Sarmah, B.K.; Higgins, T.J.V.; Romeis, J. Effectiveness of bacillus thuringiensis-transgenic chickpeas and the entomopathogenic fungus Metarhizium anisopliae in controlling Helicoverpa armigera (Lepidoptera: Noctuidae). mBio 2008, 74, 4381-4389. [CrossRef]

4. Pilz, C.; Wegensteiner, R.; Keller, S. Selection of entomopathogenic fungi for the control of the western corn rootworm Diabrotica virgifera virgifera. J. Appl. Entomol. 2007, 131, 426-431. [CrossRef]

5. Zimmermann, G. Review on safety of the entomopathogenic fungus Metarhizium anisopliae. Biocontrol. Sci. Technol. 2007, 17, 879-920. [CrossRef]

6. Maniania, N.K.; Ekesi, S. The use of entomopathogenic fungi in the control of tsetse flies. J. Invertebr. Pathol. 2013, 112, 83-88. [CrossRef] [PubMed]

7. Brandl, M.A.; Schumann, M.; Przyklenk, M.; Patel, A.; Vidal, S. Wireworm damage reduction in potatoes with an attract-and-kill strategy using Metarhizium brunneum. J. Pest. Sci. 2016, 90, 479-493. [CrossRef]

8. Faria, M.; Wraight, S.P. Mycoinsecticides and Mycoacaricides: A comprehensive list with worldwide coverage and international classification of formulation types. Biol. Control. 2007, 43, 237-256. [CrossRef]

9. Vega, F.E.; Goettel, M.S.; Blackwell, M.; Chandler, D.; Jackson, M.A.; Keller, S.; Koike, M.; Maniania, N.K.; Monzon, A.; Ownley, B.H.; et al. Fungal entomopathogens: New insights on their ecology. Fungal Ecol. 2009, 2, 149-159. [CrossRef]

10. Hu, G.; St. Leger, J. Field studies using a recombinant mycoinsecticide (Metarhizium anisopliae) reveal that it is rhizosphere competent. Appl. Environ. Microbiol. 2002, 68, 6383-6387. [CrossRef]

11. Behie, S.W.; Zelisko, P.M.; Bidochka, M.J. Ubiquity of insect-derived nitrogen transfer to plants by endophytic insect-pathogenic fungi: An additional branch of the soil nitrogen cycle. Appl. Environ. Microbiol. 2012, 80, 1553-1560. [CrossRef]

12. Barelli, L.; Moonjely, S.; Behie, S.W.; Bidochka, M.J. Fungi with multifunctional lifestyles: Endophytic insect pathogenic fungi. Plant. Mol. Biol. 2016, 90, 657-664. [CrossRef]

13. Raya-Diaz, S.; Sanchez-Rodriguez, A.R.; Segura-Fernandez, J.M.; del Campillo, M.C.; Quesada-Moraga, E. Entomopathogenic fungi-based mechanisms for improved Fe nutrition in sorghum plants grown on calcareous substrates. PLoS ONE 2017, 12, e0185903. [CrossRef]

14. Jaber, L.R.; Enkerli, J. Fungal entomopathogens as endophytes: Can they promote plant growth? Biocontrol. Sci. Technol. 2017, 27, 28-41. [CrossRef]

15. Rangel, D.E.N.; Alder-Rangel, A.; Dadachova, E.; Finlay, R.D.; Dijksterhuis, M.K.J.; Braga, G.U.L.; Corrochano, L.M.; Hallsworth, J.E. Fungal stress biology: A preface to the fungal stress responses special edition. Curr. Genet. 2015, 61, 231-238. [CrossRef]

16. Khan, A.L.; Hussain, J.; Al-Harrasi, A.; Al-Rawahi, A.; Lee, I.J. Endophytic fungi: Resource for gibberellins and crop abiotic stress resistance. Crit. Rev. Biotechnol. 2013, 35, 62-74. [CrossRef] [PubMed]

17. Meyling, N.V.; Eilenberg, J. Ecology of the entomopathogenic fungi Beauveria bassiana and Metarhizium anisopliae in temperate agroecosystems: Potential for conservation biological control. Biol. Control. 2007, 43, 145-155. [CrossRef]

18. Foley, J.A.; Defries, R.S.; Asner, G.P. Global consequences of land use. Science. 2005, 309. [CrossRef]

19. Vänninen, I. Distribution and occurrence of four entomopathogenic fungi in Finland: Effect of geographical location, habitat type and soil type. Mycol. Res. 1996, 100, 93-101. [CrossRef]

20. Jabbour, R.; Barbercheck, M.E. Soil management effects on entomopathogenic fungi during the transition to organic agriculture in a feed grain rotation. Biol. Control. 2009, 51, 435-443. [CrossRef] 
21. Kepler, R.M.; Ugine, T.A.; Maul, J.E.; Cavigelli, M.A.; Rehner, S.A. Community composition and population genetics of insect pathogenic fungi in the genus Metarhizium from soils of a long-term agricultural research system. Environ. Microbiol. 2015, 8 , 2791-2804. [CrossRef]

22. Clifton, E.H.; Jaronski, S.T.; Hodgson, E.W.; Gassmann, A.J. Abundance of soil-borne entomopathogenic fungi in organic and conventional fields in the mid-western USA with an emphasis on the effect of herbicides and fungicides on fungal persistence. Biol. Control. 2015, 51, 435-443. [CrossRef]

23. Bidochka, M.J.; Kasperski, J.E.; Wild, G.A.M. Occurrence of the entomopathogenic fungi Metarhizium anisopliae and Beauveria bassiana in soils from temperate and near-northern habitats. Canad. J. Bot. 1998, 76, 1198-1204. [CrossRef]

24. Quesada-Moraga, E.; Navas-Cortés, J.A.; Maranhao, E.A.A.; Ortiz-Urquiza, A.; Santiago-Álvarez, C. Factors affecting the occurrence and distribution of entomopathogenic fungi in natural and cultivated soils. Mycol. Res. 2007, 111, 947966. [CrossRef] [PubMed]

25. Garrido-Jurado, I.; Fernández-Bravo, M.; Campos, C.; Quesada-Moraga, E. Diversity of entomopathogenic Hypocreales in soil and phylloplane of five Mediterranean cropping systems. J. Invertebr. Pathol. 2015, 130, 97-106. [CrossRef]

26. Nielsen, C.; Skovgard, H.; Steenberg, T. Effect of Metarhizium anisopliae (Deuteromycotina: Hyphomycetes) on survival and reproduction of the filth fly parasitoid, Spalangia cameroni (Hymenoptera: Pteromalidae). Environ. Entomol. 2004, 34, 133-139. [CrossRef]

27. Keller, S.; Kessler, P.; Schweizer, C. Distribution of insect pathogenic soil fungi in Switzerland with special reference to Beauveria brongniartii and Metharhizium anisopliae. BioControl. 2003, 48, 307-319. [CrossRef]

28. Schneider, S.; Widmer, F.; Jacot, K.; Kolliker, R.; Enkerli, J. Spatial distribution of Metarhizium clade 1 in agricultural landscapes with arable land and different semi-natural habitats. Appl. Soil. Ecol. 2012, 52, 20-28. [CrossRef]

29. Klingen, I.; Eilenberg, J.; Meadow, R. Effects of farming system, field margins and bait insect on the occurrence of insect pathogenic fungi in soils. Agric. Ecosyst. Environ. 2002, 91, 191-198. [CrossRef]

30. Miętkiewski, R.T.; Pell, K.J.; Clark, S.J. Influence of pesticide use on the natural occurrence of entomopathogenic fungi in arable soil in the UK: Field and laboratory comparisons. Biocontrol. Sci. Technol. 1997, 7, 565-575. [CrossRef]

31. Cabrera-Mora, J.A.; Guzmán-Franco, A.W.; Santillán-Galicia, M.T.; Tamayo-Mejía, F. Niche separation of species of entomopathogenic fungi within the genera Metarhizium and Beauveria in different cropping systems in Mexico. Fungal Ecol. 2019, 39, 349-355. [CrossRef]

32. Wyrebek, M.; Huber, C.; Sasan, R.K.; Bidochka, M.J. Three sympatrically occurring species of Metarhizium show plant rhizosphere specificity. Microbiology 2011, 157, 2904-2911. [CrossRef]

33. Bidochka, M.J.; Kamp, A.M.; Lavender, T.M.; Dekoning, J.; De Croos, J.N.A. Habitat association in two genetic groups of the insect-pathogenic fungus Metarhizium anisopliae: Uncovering cryptic species? Appl. Environ. Microbiol. 2001, 67, 1335-1342. [CrossRef] [PubMed]

34. Bidochka, M.J.; Small, C.L. Phylogeography of Metarhizium, an insect pathogenic fungus. In Insect-Fungal Associations: Ecology and Evolution; Vega, F.E., Blackwell, M., Eds.; Oxford University Press: New York, NY, USA, 2005; pp. 75-118.

35. Bischoff, J.F.; Rehner, S.A.; Humber, R.A. A multilocus phylogeny of the Metarhizium anisopliae lineage. Mycologia. 2009, 101, 512-530. [CrossRef] [PubMed]

36. Steinwender, B.M.; Enkerli, J.; Widmer, F.; Eilenberg, J.; Thorup-Kristensen, K.; Meyling, N.V. Molecular diversity of the entomopathogenic fungal Metarhizium community within an agroecosystem. J. Invertebr. Pathol. 2014, 123, 6-12. [CrossRef] [PubMed]

37. Castro, T.; Mayerhofer, J.; Enkerli, J.; Eilenberg, J.; Meyling, N.V.; Moral, R.D.; Demetrio, C.G.B.; Delalibera, I. Persistence of Brazilian isolates of the entomopathogenic fungi Metarhizium anisopliae and M. robertsii in strawberry crop soil after soil drench application. Agric. Ecosyst. Environ. 2016, 233, 361-369. [CrossRef]

38. Inglis, G.D.; Duke, G.M.; Goettel, M.S.; Kabaluk, J.T.; Ortega-Polo, R. Biogeography and genotypic diversity of Metarhizium brunneum and Metarhizium robertsii in northwestern North American soils. Can. J. Microbiol. 2019, 65, 261-281. [CrossRef]

39. Ekesi, S.; Maniania, N.K.; Ampong-Nyarko, K. Effect of temperature on germination, radial growth and virulence of Metarhizium anisopliae and Beauveria bassiana on Megalurothrips sjostedti. Biocontrol Sci. Technol. 1999, 9, 177-185. [CrossRef]

40. Rangel, D.E.N.; Braga, G.U.L.; Anderson, A.J.; Roberts, D.W. Variability in conidial thermotolerance of Metarhizium anisopliae isolates from different geographic regions. J. Invertebr. Pathol. 2005, 88, 116-125. [CrossRef] [PubMed]

41. Fernández-Bravo, M.; Flores-León, A.; Calero-López, S.; Gutiérrez-Sánchez, F.; Valverde-García, P.; Quesada-Moraga, E. UV-B radiation-related effects on conidial inactivation and virulence against Ceratitis capitata (Wiedemann) (Diptera; Tephritidae) of phylloplane and soil Metarhizium sp. Strains. J. Invertebr. Pathol. 2017, 148, 142-151. [CrossRef]

42. McGuire, A.V.; Northfield, T.D. Tropical Occurrence and Agricultural Importance of Beauveria bassiana and Metarhizium anisopliae. Front. Sustain. Food. Syst. 2020, 4, 6. [CrossRef]

43. Uzman, D.; Pliestera, J.; Leyerb, I.; Entlingc, M.H.; Reinekea, A. Drivers of entomopathogenic fungi presence in organic and conventional vineyard soils. Appl. Soil Ecol. 2019, 133, 89-97. [CrossRef]

44. Medo, J.; Cagán, M. Factors affecting the occurrence of entomopathogenic fungi in soils of Slovakia as revealed using two methods. Biol. Control. 2011, 59, 200-208. [CrossRef]

45. Gubler, A.; Schwab, P.; Wächter, D.; Meuli, R.G.; Keller, A. Ergebnisse der Nationalen Bodenbeobachtung (NABO) 1985-2009. Zustand und Veränderungen der anorganischen Schadstoffe und Bodenbegleitparameter; Bundesamt für Umwelt-Umwelt-Zustand: Bern, Germany, 2015; pp. 1-81. 
46. Gschwend, F.; Hartmann, M.; Hug, A.; Enkerli, J.; Gubler, A.; Frey, B.; Meuli, R.G.; Widmer, F. Long-term stability of soil bacterial and fungal community structures revealed in their abundant and rare fractions. Mol. Ecol. 2021, in press. [CrossRef] [PubMed]

47. Gubler, A.; Wächter, D.; Schwab, P.; Müller, M.; Keller, A. Twenty-five years of observations of soil organic carbon in Swiss croplands showing stability overall but with some divergent trends. Environ. Monit. Assess. 2019, 191, 277. [CrossRef]

48. Strasser, H.; Forer, A.; Schinner, F. Development of media for the selective isolation and maintenance of virulence of Beauveria brongniartii. In Microbial Control of Soil Dwelling Pests; Jackson, T., Glare, T., Eds.; Christchurch, AgResearch Publisher: Lincoln, New Zealand, 1996; pp. 125-130.

49. Barnett, H.L.; Hunter, B.B. Illustrated Genera of Imperfect Fungi; APS Press: St. Paul, MN, USA, 2006.

50. Rehner, S.A.; Buckley, E.P. A Beauveria phylogeny inferred from nuclear ITS and EF1-alpha sequences: Evidence for cryptic diversification and links to Cordyceps teleomorphs. Mycologia 2005, 97, 84-98. [CrossRef]

51. Mayerhofer, J.; Rauch, H.; Hartmann, M.; Widmer, F.; Gschwend, F.; Strasser, H.; Leuchtmann, A.; Enkerli, J. Response of soil microbial communities to the application of a formulated Metarhizium brunneum biocontrol strain. Biocontrol Sci. Technol. 2019, 29, 547-564. [CrossRef]

52. Kumar, S.; Stecher, G.; Li, M.; Knyaz, C.; Tamura, K. MEGA X: Molecular evolutionary genetics analysis across computing platforms. Mol. Biol. Evol. 2018, 35, 1547-1549. [CrossRef]

53. Kimura, M. A simple method for estimating evolutionary rates of base substitutions through comparative studies of nucleotide sequences. J. Mol. Evol. 1980, 16, 111-120. [CrossRef]

54. Mayerhofer, J.; Lutz, A.; Widmer, F.; Rehner, S.A.; Leuchtmann, A.; Enkerli, J. Multiplexed microsatellite markers for seven Metarhizium species. J. Invertebr. Pathol. 2015, 132, 132-134. [CrossRef]

55. Kamvar, Z.N.; Tabima, J.F.; Grünwald, N.J. Poppr: An R package for genetic analysis of populations with clonal, partially clonal, and/or sexual reproduction. Peer] 2014, 2, e281. [CrossRef] [PubMed]

56. Shannon, C.E. A mathematical theory of communication. Bell Syst. Tech. 1948, 27, 379-423. [CrossRef]

57. Pielou, E. Ecological Diversity; John Wiley and Sons: Hoboken, NJ, USA, 1975.

58. Ludwig, J.; Reynolds, J. Statistical Ecology. A Primer on Methods and Computing; John Wiley and Sons: Hoboken, NY, USA, 1988.

59. Grünwald, N.J.; Goodwin, S.B.; Milgroom, M.G.; Fry, W.E. Analysis of genotypic diversity data for populations of microorganisms. Phytopathology 2003, 93, 738-746. [CrossRef] [PubMed]

60. Bray, J.R.; Curtis, J.T. An ordination of the upland forest communities of southern Wisconsin. Ecol. Monogr. 1957, 27, 326-349. [CrossRef]

61. Hervé, M. RVAideMemoire: Testing and Plotting Procedures for Biostatistics. R Package Version 0.9-69-3; RStudoi: Boston, MA, USA, 2018.

62. Oksanen, J.; Blanchet, G.F.; Friendly, M.; Kindt, R.; Legendre, P.; McGlinn, D.; Wagner, H. Vegan: Community Ecology Package. R Package Version 2.4-6; RStudoi: Boston, MA, USA, 2018; Available online: http:/ /CRAN.R-project.org/package=vegan (accessed on 27 May 2021).

63. R-Core-Team. R: A Language and Environment For Statistical Computing; R Foundation for Statistical Computing: Vienna, Austria, 2016.

64. Gower, J.C. Some distance properties of latent root and vector methods used in multivariate analysis. Biometrika 1966, 53, 325-328. [CrossRef]

65. Shah, F.A.; Wang, C.S.; Butt, T.M. Nutrition influence growth and virulence of the insect-pathogenic fungus Metarhizium anisopliae. FEMS Microbiol. Lett. 2005, 251, 259-266. [CrossRef]

66. Gao, L.; Sun, M.H.; Liu, X.Z.; Che, Y.S. Effects of carbon concentration and carbon to nitrogen ratio on the growth and sporulation of several biocontrol fungi. Mycol. Res. 2007, 111, 87-92. [CrossRef]

67. Ortiz-Urquiza, A.; Garrido-Jurado, I.; Borrego, A.; Quesada-Moraga, E. Effects of cultural conditions on fungal biomass, blastospore yields and toxicity of fungal secreted proteins in batch cultures of Metarhizium anisopliae (Ascomycota: Hypocreales). Pest. Manag. Sci. 2010, 66, 725-735. [CrossRef]

68. Sehler, R.; Li, J.; Reager, J.T.; Ye, H. Investigating relationship between soil moisture and precipitation globally using remote sensing observations. J. Contemp. Water Res. Educ. 2019, 168, 106-118. [CrossRef]

69. Garrido-Jurado, I.; Valverde-Garcia, P.; Quesada-Moraga, E. Use of a multiple logistic regression model to determine the effects of soil moisture and temperature on the virulence of entomopathogenic fungi against pre-imaginal Mediterranean fruit fly Ceratitis capitata. Biol. Control. 2011, 59, 366-372. [CrossRef]

70. Sosa-Gómez, D.R.; Delpin, K.E.; Moscardi, F.; Farias, J.R.B. Natural occurrence of the entomopathogenic fungi Metarhizium, Beauveria and Paecilomyces in soybean under till and no-till cultivation systems. Neotrop. Entomol. 2001, 30, 407-410. [CrossRef]

71. Hummel, R.L.; Walgenbach, J.F.; Barbercheck, M.E.; Kennedy, G.G.; Hoyt, G.D.; Arellano, C. Effects of production practices on soil-borne entomopathogens in western North Carolina vegetable systems. Environ. Entomol. 2002, 31, 84-91. [CrossRef]

72. Inglis, G.D.; Duke, G.M.; Goettel, M.S.; Kabaluk, J.T. Genetic diversity of Metarhizium anisopliae var. anisopliae in southwestern British Columbia. J. Invertebr. Pathol. 2007, 98, 101-113. [CrossRef]

73. Rehner, S.A. Genetic structure of Metarhizium species in western USA: Finite populations composed of divergent clonal lineages with limited evidence for recent recombination. J. Invertebr. Pathol. 2020, 177, 107491. [CrossRef] [PubMed] 
74. Fisher, J.J.; Rehner, S.A.; Bruck, D.J. Diversity of rhizosphere associated entomopathogenic fungi of perennial herbs, shrubs and coniferous trees. J. Invertebr. Pathol. 2011, 106, 289-295. [CrossRef] [PubMed]

75. Arribas, P.; Andújar, C.; Salces-Castellano, A.; Emerson, B.C.; Vogler, A.P. The limited spatial scale of dispersal in soil arthropods revealed with whole-community haplotype-level metabarcoding. Mol. Ecol. 2021, 30, 48-61. [CrossRef]

76. Dromph, K.M. Collembolans as vectors of entomopathogenic fungi. Pedobiologia 2003, 47, 245-256. [CrossRef] 